\title{
Antibacterial, antioxidant and anticancer properties of Turbinaria conoides (J. Agardh) Kuetz
}

Arumugama Ponnan ${ }^{1 *}$, Kavipriya Ramu ${ }^{2}$, Murugan Marudhamuthu $^{3}$, Ramar Marimuthu$^{1}$, Kamalakannan Siva ${ }^{1}$ and Murugan Kadarkarai ${ }^{1}$

\begin{abstract}
Background: Cancer causes leading death in the world population due to exposure of various carcinogenic/mutagenic agents, radiation and life style. There are 2.6 million new cases diagnosed each year. Therefore, the objective is aimed to study the antibacterial and antioxidant activities of solvent fractions of ethanolic extract of $T$. conoides and its anticancer activity also evaluated by analyzing cytotoxicity, cell cycle arrest and apoptosis in HepG2 cell line.

Methods: Antibacterial activity was done by disc diffusion method and expressed as in millimeter diameter of zone inhibition. Antioxidant activity was done by ABTS radical assay, superoxide radical assay, iron chelation and uric acid formation inhibitory assays. The cytotoxicity efficacy was estimated using MTT assay. Annexin-V FITC kit was used to estimate the apoptosis and cell cycle arrest by flowcytometer. Morphological changes of cell through alteration of nuclear content and mitochondrial membrane potential were also examined using Hoechst and JC1 stains under fluorescence microscopy, respectively.
\end{abstract}

Results: Highest antibacterial activity, TAA and RAA were found in EAF followed by DMF, HF and AF. Cytotoxicity of EAF was found to be $67 \%$ at $24 \mathrm{~h}$ and $83 \%$ at $48 \mathrm{~h}$ over the standard of quercetin ( $86 \%$ at $48 \mathrm{~h}$ ). The cancer cells were found to be significantly $(p<0.05)$ higher in the proliferative G0/G1 phase where as significantly decreased in the $\mathrm{S}$ phase.

Hence, treatment with $T$. conoides fraction showed statistically $(p<0.05)$ significant increase of apoptotic cells than that of quercetin standard $(32 \%, 80 \mathrm{\mu g} / \mathrm{mL})$. The apoptotic cell formation might be due to the change of nuclear content and mitochondrial membrane potential were further confirmed in HepG2 cells under fluorescence microscopy.

Conclusion: Ethyl acetate fraction of T. conoides showed highest antibacterial, antioxidant and anticancer activity through exhibiting synergistic effects over the respective standard compounds.

Keywords: Tubunaria conoides, Antibacterial, Antioxidant, Anticancer, HepG2 cell line

\section{Background}

The recent scientific trends focus on search of phytochemicals from marine algae due to their numerous health-promoting effects, including antioxidant, antiinflammatory, antimicrobial, and anti-cancer [1]. Antioxidant is a well know natural substance that can be taken up by human population to protect various disease and disorders such as melanoma, cardiac disorders, diabetes mellitus and neurodegenerative diseases etc. It is reported

\footnotetext{
* Correspondence: ponnanarumugam@gmail.com

${ }^{1}$ Department of Zoology, School of Life Science, Bharathiar University,

Coimbatore 641 046, Tamil Nadu, India

Full list of author information is available at the end of the article
}

that antioxidant also enhanced the shelf life of food and medicine [2]. Brown seaweeds possessed potential source of novel antioxidants which are more acceptable than synthetic antioxidants due to the absence of chemical contaminants [3]. Nowadays, different compounds of marine macroalgae are believed to exhibit potent antioxidant activity. Especially, phenolic compounds and other compounds such as carotenoids, ascorbic acid, glutathione, and sulphated polysaccharides are powerful antioxidant molecules identified in macroalgae $[4,5]$.

Tubunaria conoides belongs to the family of Sargassaceae (brown algae) is coming under the order of Fucales. It has traditionally been used for children's fever, as a fertilizer, 
insect repellent, pesticide and antibacterialcidal [6]. Phytochemicals such as steroids, phenolics, flavonoids, reducing sugars, fucosterol, sulfated polysaccharides including fucoidan, neutral glucan, guluronic and alginic acid were reported to be presence in T. conoides [7]. It is also possessed other essential components, digestible proteins along with mineral salts (K, Ca, and Fe) and polyunsaturated fatty acids. Apart, it has a wealthy source of dietary fiber content with iodine which is play an immense role in enhancing the food quality and biochemical homeostasis [8]. Hence, the cytotoxicity of $T$. conoides was reported in ethyl acetate extract due to its oxygenated fucosterols $[9,10]$. Consecutive extraction of $T$. conoides with $n$-hexane, cyclohexane, methanol and ethanol: water (1:1) were also documented with their antibacterial and antifungal activities by disc diffusion method. In which, cyclohexane extract was possessed a broad array of antibacterial activity and exhibited remarkable antifungal property over the other extracts [6]. Turbinaria spp such as T. conoides and T. ornata collected from Gulf of Mannar of Southeastern coast of India were also reported to possess antioxidant activity in ethyl acetate fractions due to the presence of total phenolic contents [11]. Hence, several literatures emphasized that the potential implication of marine products from brown seaweeds exhibited antitumour activity. Sodium alginate obtained from brown seaweeds possessed various biological properties like removal of heavy metal, antitumour and anti-inflammatory property [12]. Therefore, natural antioxidants are considered as a safe ingredient in medicine, dietary supplements, nutraceuticals and cosmetics preparation with the objective of improving consumer health, reducing the effects of harmful diseases and other broader aspects of immune functions [13].

Liver cancer is one of the leading causes of cancer death in the world [14]. Tumor initiation, progression, and maintenance commonly involved alteration in apoptosis. Studies have shown that dysregulation of apoptosis is an important cause for the hepatocarcinogenesis [15]. The induction of apoptosis is a crucial event for prevention of cancer by naturally occurring dietary agents [16]. In fact, lack of curative therapies and their associated potential adverse effects are crucial events in cancer disease and therefore new strategies is required to address those issue of liver cancer. One such strategy might include incorporating large amounts of natural compounds thought to have an anticancer effect either in diet or to ingest a dietary supplement containing an efficacious quantity of such a compound. Such thoughts have turned the direction of research towards phytochemical preparation and dietary supplements for combating hepatocarcinogenesis [17]. Therefore, in the present investigation aimed to study the antibacterial and antioxidant activities of solvent fraction of ethanol extract of $T$. conoides and its anticancer properties evaluated by analyzing cytotoxicity, cell cycle arrest and apoptosis in HepG2 cell line.

\section{Methods}

\section{Chemicals}

Annexin V-FITC assay kit, Hoechst 33342, 5,5'6,6' -tetrachloro-1,1'3,3'tetraethylbenzimi-dazolycarbocyanine iodide (JC-1) staining solution, NBT, xanthine oxidase (EC 1.1.3.22, Grade IV), ABTS, xanthine, quercetin, $\beta$-carotene and ASC were obtained from Sigma-Aldrich, USA. Ferric chloride, potassium ferricyanide, Potassium persulfate and ferrozine were obtained from Sisco Research Laboratory Pvt. Ltd. India and EDTA from Hi-mediai, India. All solvents used in this study were of analytical grade.

\section{Seaweed collection and preparation of solvent fractions}

The brown seaweed of T. conoides (J. Agardh) Kuetz was collected from the intertidal zone of Mandapam, Gulf of Mannar, Southeast Coast of Tami Nadu, India. The algae samples $(1 \mathrm{~kg})$ were washed with fresh tap water followed by distilled water to remove salt and other debris along with necrotic parts. Samples were made into small pieces and shade dried after then powdered using a mixer grinder. The powdered sample was stored in a polyethylene bag at room temperature. The shade dried powder $250 \mathrm{~g}$ was immersed in a $2 \mathrm{~L}$ of 2 conical flasks with each $1.25 \mathrm{~L}$ of $95 \%$ ethanol and left for $24 \mathrm{~h}$ under constant stirring. After the $24 \mathrm{~h}$, transfer from conical flask to Soxhlet apparatus and extracts was collected in bottom flask at $40{ }^{\circ} \mathrm{C}$ and this was repeated twice with $2.5 \mathrm{~L}$ of $95 \%$ ethanol. Final volume of $4.5 \mathrm{~L}$ ethanol extract was brought out into $25 \mathrm{~g}$ (10\%) with rotary evaporator. The ethanol extract was transfer into a separating funnel and partitioned between distilled water and hexane with 1:6 ratio [18]. This mixture was thoroughly mixed for $15 \mathrm{~min}$ and then hexane fraction (HF) was collected 1.4 L after $1 \mathrm{~h}$ incubation. Similarly, aqueous layer $250 \mathrm{~mL}$ was further fractionated with dichloromethane (DMF) and ethyl acetate (EAF). All the fractions were concentrated in rotary evaporator. The yield of the fractions was 20, 16, and 52\% respectively. The aqueous fraction (AF) was lyophilized and obtained $12 \%$ of yield.

\section{Qualitative analysis of secondary metabolites}

Based on the method described by Allen [19] and Harbone [20] the following major phytochemicals such as alkaloids, tannins, saponins, terpenoids, phenols, flavonoids, coumarin, glycosides, reducing sugar, steroids and resins were spectrophotometrically analyzed in ethanol extract of $T$. conoides.

\section{Antibacterial assay using a disc diffusion method}

Antibacterial activity was measured using a disc diffusion method described by Mackeen et al. [21]. Standard antibiotic, streptomycin was used as positive control. For antibacterial screening, $8 \mu \mathrm{g}$ of solvent fractions was 
loaded onto each disc (6 mm diameter) and placed on previously inoculated agar plate with clinically important both gram positive and negative bacteria. The plates were incubated for $24 \mathrm{~h}$ at $37{ }^{\circ} \mathrm{C}$. Diameter of zone inhibition around the disc were measured and expressed as in millimeter.

\section{Quantification of total antioxidants in solvent fractions}

The $\mathrm{ABTS}^{+}$radical preparation and antioxidant quantification were clearly given in the previous article ${ }^{19}$. The assay was performed in one $\mathrm{mL}$ reaction volume. HF, DMF, EAF and AF were tested at concentration with range of $0-80 \mu \mathrm{g} / \mathrm{mL}$. $\beta$-carotene and L-ascorbic were used as standard antioxidants. Appropriate blanks were run in each assay and all the experiments were carried out in five replications and the values were averaged. The TAA and RAA were calculated and expressed based on the formula in the previous study [18].

\section{Superoxide radical scavenging activity}

According to Tota and Kumura [22], the superoxide radical was generated by xanthine oxidase system. The reaction mixture consisted of $2.70 \mathrm{~mL}$ of $40 \mathrm{mM}$ sodium carbonated buffer which included $0.1 \mathrm{mM}$ EDTA (pH 10.0), $0.06 \mathrm{~mL}$ of $10 \mathrm{mM}$ xanthine, $0.03 \mathrm{~mL}$ of $0.5 \%$ bovine serum albumin, $0.03 \mathrm{~mL}$ of $2.5 \mathrm{mM} \mathrm{NBT}$, and $0.06 \mathrm{~mL}$ of EAF $(0-80 \mu \mathrm{g} / \mathrm{mL})$ or ascorbic acid $(30 \mu \mathrm{g} /$ $\mathrm{mL})$. The mixture was kept at room temperature $\left(25^{\circ} \mathrm{C}\right)$ for $20 \mathrm{~min}$ and after $0.12 \mathrm{~mL}$ of xanthine oxidase $(0.04$ units) was added. The absorbance at $560 \mathrm{~nm}$ was recorded (formation of blue formazan) after $5 \mathrm{~min}$ with five readings. The results were expressed as percentage of radical scavenging activity.

\section{Estimation of iron chelation activity}

The reaction mixture contains $100 \mu \mathrm{L}$ of $1 \mathrm{mM} \mathrm{FeCl}_{2}$, $3.7 \mathrm{~mL}$ of distilled water and $1 \mathrm{~mL}$ aliquot of the EAF $(0-80 \mu \mathrm{g} / \mathrm{mL}) / \mathrm{standard}$, EDTA $(3 \mathrm{mg} / \mathrm{mL})$. The reaction was initiated by adding $200 \mu \mathrm{L}$ of $5 \mathrm{mM}$ ferrozine. The reaction mixture was incubated at room temperature for $20 \mathrm{~min}$ and the absorbance was recorded at $562 \mathrm{~nm}$ [23]. The iron chelating activity of EAF was calculated and expressed as percentage.

\section{Uric acid formation inhibitory activity}

The reaction mixture consisted of $2.76 \mathrm{~mL}$ of $40 \mathrm{mM}$ sodium carbonate buffer which included 0.1 mM EDTA (pH 10.0), $0.06 \mathrm{~mL}$ of $10 \mathrm{mM}$ xanthine, and $0.06 \mathrm{~mL}$ of EAF $(0-80 \mu \mathrm{g} / \mathrm{mL})$ or ascorbic acid $(30 \mu \mathrm{g} / \mathrm{mL})$. The reaction was started by the addition of $0.12 \mathrm{~mL}$ of xanthine oxidase $(0.04$ units) and the absorbance at $293 \mathrm{~nm}$ was recorded after $5 \mathrm{~min}$ with five readings at room temperature [22]. The results were expressed as percentage of uric acid formation by EAF.

\section{Cytotoxicity assay}

The cell line study was carried out at AU-KBC Research Centre, Anna University, Chennai, India. The cytotoxicity assay performed using MTT assay as described by Mosmann [24]. Tetrazolium salt MTT solution prepared freshly in concentration of $0.5 \mathrm{mg} / \mathrm{mL}$ of PBS. Cells seeded in 96 -well plates $\left(1 \times 10^{5}\right.$ cells/well $)$ and allowed to adhere for $6 \mathrm{~h}$. The cells were treated with different concentrations $(0-320 \mu \mathrm{g} / \mathrm{mL})$ of EAF /quercetin after filtered through $0.2 \mu$ Millipore filter and kept for 24 and $48 \mathrm{~h}$. Consequently, $100 \mu \mathrm{L}$ of MTT dye $(5 \mathrm{mg}$ in $10 \mathrm{ml}$ of serum free medium) added in each well. Control also maintained in the same manner. The plates were incubated at $5 \% \mathrm{CO}_{2}$ incubator for $4 \mathrm{~h}$. The formazan crystals dissolved in $100 \mu \mathrm{L}$ of $20 \%$ SDS (in $50 \%$ dimethyl formamide) and the measured optical density (OD) using a 96 well microplate reader at $570 \mathrm{~nm}$. The inhibition ratio (I \%) calculated using the following equation: I\% $=($ Acontrol-Atreated $) /$ Acontrol $\times 100 \%$.

\section{Flow cytometric analysis of cell cycle}

Cells seeded into 6-well culture plates and exposed to EAF/quercetin at the concentrations $(0-320 \mu \mathrm{g} / \mathrm{mL})$ for 48 h. After treatment, cells $\left(1 \times 10^{6}\right.$ cells $\left./ \mathrm{mL}\right)$ were collected and fixed with $70 \%$ ice-cold ethanol (v/v) and stored at $-20{ }^{\circ} \mathrm{C}$ overnight. The fixed cells washed twice with PBS and incubated for $30 \mathrm{~min}$ in the dark at room temperature with $1 \mathrm{~mL}$ of PBS containing PI $(20 \mu \mathrm{g} /$ $\mathrm{mL}), 0.1 \%(\mathrm{v} / \mathrm{v})$ Triton X-100 and $0.1 \%$ RNase A [25]. A total of at least 30, 000 events were collected and analyzed by flowcytometer. The percentage of cells in G0/G1, S and G2/M phases was determined using the Cell Quest acquisition software.

\section{Flow cytometric analysis of apoptosis}

The annexin V-FITC assay was performed according to the manufacture's protocol. Briefly, cells were seeded into 6-well plates and incubated for $48 \mathrm{~h}$ with different concentration $(0-320 \mu \mathrm{g} / \mathrm{mL})$ of EAF and quercetin. Cells $\left(1 \times 10^{6}\right.$ cells $\left./ \mathrm{mL}\right)$ washed twice with PBS and resuspended in $500 \mu \mathrm{L}$ of binding buffer containing $5 \mu \mathrm{L}$ of FITC conjugated annexin-V and $5 \mu \mathrm{L}$ of PI. The plates were incubated in the dark for $15 \mathrm{~min}$ at ambient temperature and after analyzed by flowcytometry within a $1 \mathrm{~h}$ period. The percentage of total apoptotic cells was calculated by the addition of both early and late apoptotic evens.

\section{Detection of nuclear condensation by Hoechst assay}

Cells treated with EAF of T. conoides $(320 \mu \mathrm{g} / \mathrm{mL})$ for $48 \mathrm{~h}$ and then cells were washed with PBS and fixed with methanol: acetic acid (3:1) for $15 \mathrm{~min}$ at room temperature. Fixed cells then washed with PBS and stained with $5 \mu \mathrm{g} /$ $\mathrm{mL}$ of Hoechst 33342 stain for $10 \mathrm{~min}$. Changes in the 
morphology of nuclei in the cells were observed using a fluorescence microscope [26].

\section{Detection of mitochondrial membrane potential by JC-1 assay}

The mitochondrial membrane potential $(\Delta \Psi \mathrm{m})$ was analyzed using the 5,5'6,6'-tetrachloro-1,1'3,3'tetraethylbenzimi-dazolycarbocyanine iodide (JC-1) by fluorescence microscopy. Cells treated with EAF of $T$. conoides $(320 \mu \mathrm{g} / \mathrm{mL})$ for $48 \mathrm{~h}$ and after $5 \mu \mathrm{l}$ of the JC- 1 staining solution with $1 \mathrm{ml}$ culture of medium was added to each well. Samples incubated in $5 \% \mathrm{CO}_{2}$ incubator at $37{ }^{\circ} \mathrm{C}$ for 20 min. Then, cells washed twice with PBS buffer solution and visualized under a fluorescence microscope [26].

\section{Statistical analysis}

The results were expressed as a mean \pm SD/SE with three or five values. All the data were analyzed statistically by One-way ANOVA followed by Tukey's multiple comparisons using SPSS software student's version-16. A $p$ value $<0.05$ was considered statistically significant.

\section{Results}

Turbnaria conoides shade dried powder was immersed with ethanol solvent and extracted with Soxhlet apparatus. Presence of secondary metabolites such as alkaloids, tannins, saponins, terpenoids, phenols, flavonoids, coumarin, glycosides, reduced sugar, steroids and resins were screened. Except resins and alkaloid, all other secondary metabolites were found to be presence in the ethanol extract (Table 1). Ethanol extract was further fractionated with sequential solvents such as hexane, dichloromethane, ethyl acetate, and water. These solvent fractions were used to determine their antibacterial and total antioxidant activities.

Table 1 Phytochemical profile obtained from ethanol extract of T. conoides

\begin{tabular}{ll}
\hline Secondary metabolites & Aqueous extract \\
\hline Alkaloids & - \\
Tannins & + \\
Saponins & + \\
Terpenoids & + \\
Phenols & + \\
Flavonoids & + \\
Coumarin & + \\
Glycosides & + \\
Reduced sugar & + \\
Steroids & - \\
Resins & - \\
\hline
\end{tabular}

('+' presence \& '-'absence)
Antibacterial activity of solvent fractions of ethanol extract/standard, streptomycin was studied by disc diffuse method with more than ten clinically important bacteria. The highest antibacterial activity was found in ethyl acetate fraction followed by dichloromethane, hexane and aqueous fractions. Ethyl acetate fraction exhibited 13-28 $\mathrm{mm}$ in diameter zone of inhibition whereas other fractions such as dichloromethane, hexane and water fractions showed in the range of 10-24, 5-17 and 5-9 $\mathrm{mm}$ in diameter zone of inhibition, respectively. Antibacterial activity of ethyl acetate fraction was observed to be more comparable to the standard of streptomycin. However, aqueous fraction was not able to exhibit any responds against $50 \%$ of bacteria tested (Table 2 ).

TAAs and RAAs were estimated in all the four fractions along with known antioxidant such as $\beta$-carotene and L-ascorbic acid (Table 3). TAA of solvent fractions were tested using $10-80 \mu \mathrm{g} / \mathrm{mL}$ concentrations whereas RAA calculated with maximum TAA of $\beta$-carotene and $\mathrm{L}$-ascorbic acid. TAA was found to be in the range of $08-46 \%$ in $\mathrm{HF}, 13-55 \%$ in DMF, $26-85 \%$ in EAF and $05-35 \%$ in AF. The maximum TAA was obtained $85 \%$ at the $80 \mu \mathrm{g} / \mathrm{mL}$ concentration of EAF and least $5 \%$ at the $10 \mu \mathrm{g} / \mathrm{mL}$ concentration of AF. TAA of DMF exhibited significantly over the HF and AF. Similarly, the RAA was also found to be the same as like as TAA. The maximum RAA was observed $\geq 1$ in the EAF followed by DMF, HF and AF against in both standard antioxidants.

EAF was further analyzed against superoxide anion radical, iron chelation and uric acid formation inhibitory activity (Table 4). Superoxide radical scavenging activity of EAF was observed in the range of $23-77 \%$ at the $10-80 \mu \mathrm{g} / \mathrm{mL}$ concentrations which was more comparable to the standard of ascorbic acid (74\% at $30 \mu \mathrm{g} / \mathrm{mL})$. Hence, Iron chelation of ethyl acetate fraction showed $16-70 \%$ at the $10-80 \mu \mathrm{g} / \mathrm{mL}$ concentrations which was less comparable to the standard of EDTA $(79 \%$ at $3 \mathrm{mg} / \mathrm{mL})$. Uric acid formation inhibitory activity was also found to be in the range of 15$66 \%$ which was also less comparable to the standard of ascorbic acid $(75 \%$ at $30 \mu \mathrm{g} / \mathrm{mL})$. The results revealed that antioxidant activities of EAF were observed to be concentration dependent.

Cytotoxicity of EAF of $T$. conoides was tested by MTT assay. The cancer cells showed considerable and dose dependent susceptibility to the EAF (80-320 $\mu \mathrm{g} /$ $\mathrm{mL}$ ) and known standard of quercetin. Cytotoxicity of EAF was found to be $30-70 \%$ and $46-83 \%$ where as quercetin $35-73 \%$ and $44-86 \%$ at the $24 \mathrm{~h}$ and $48 \mathrm{~h}$ of time intervals, respectively. Moreover, ethyl acetate fraction exhibited cytotoxicity as equal as quercetin at their maximum concentration $(320 \mu \mathrm{g} / \mathrm{mL}$ and $160 \mu \mathrm{g} /$ $\mathrm{mL})$. Cytotoxicity revealed time-dependent growth inhibition of cancer cells (Fig. 1). 
Table 2 Solvent fractions of ethanol extract of T. conoides on human pathogenic bacteria

\begin{tabular}{llllllr}
\hline S.No & Organism name & HF & DMF & EAF & AF & Streptomycin \\
\hline 1 & Bacillus subtilis & $17 \pm 2.00$ & $24 \pm 2.00$ & $28 \pm 2.00$ & $5 \pm 2.00$ & $30 \pm 4.00$ \\
2 & Enterococcus faecalis & $09 \pm 2.65$ & $12 \pm 2.00$ & $15 \pm 2.00$ & $8 \pm 2.00$ & $18 \pm 3.00$ \\
3 & Staphylococcus aureus & $16 \pm 2.00$ & $18 \pm 2.00$ & $20 \pm 2.08$ & $7 \pm 2.00$ & $32 \pm 2.00$ \\
4 & Escherichia coli & $13 \pm 1.00$ & $19 \pm 2.00$ & $20 \pm 2.00$ & $7 \pm 1.00$ & $26 \pm 3.00$ \\
5 & Klebsiella pneumoniae & $07 \pm 2.00$ & $10 \pm 1.00$ & $14 \pm 2.00$ & $9 \pm 2.65$ & $21 \pm 2.65$ \\
6 & Proteus vulgaris & $13 \pm 2.00$ & $16 \pm 2.00$ & $13 \pm 1.00$ & - & $20 \pm 4.00$ \\
7 & Pseudomonas aeruginosa & $11 \pm 1.00$ & $15 \pm 1.00$ & $16 \pm 2.00$ & - & $-19 \pm 2.00$ \\
8 & Salmonella paratyphi & $15 \pm 1.00$ & $19 \pm 1.00$ & $22 \pm 2.00$ & - & $28 \pm 2.00$ \\
9 & Salmonella typhi & $17 \pm 2.65$ & $21 \pm 2.00$ & $25 \pm 3.00$ & - & $31 \pm 2.65$ \\
10 & Shigella boydii & $05 \pm 1.00$ & $11 \pm 1.00$ & $15 \pm 2.65$ & $6 \pm 1.00$ & $24 \pm 3.61$ \\
11 & Vibrio cholerae & $04 \pm 2.00$ & $10 \pm 2.00$ & $13 \pm 3.00$ & - & $19 \pm 2.00$ \\
\hline
\end{tabular}

Values are expressed as a mean (mm diameter of zone inhibition) \pm standard deviation $(n=3)$; HF hexane fraction, DMF dichloromethane fraction, EAF ethyl acetate fraction, $A F$ aqueous fraction

EAF of $T$. conoides whether affects the cell cycle progression was carried out with PI staining by flowcytometer. Histogram shows that the cancer cells could be categorized into three groups G0/G1, S, and G2/M phases (Fig. 2). The results revealed that the number of accumulated cancer cells was significantly $(p<0.05)$ higher in the proliferative G0/G1 phase where as significant decrease in the $\mathrm{S}$ phase, after $48 \mathrm{~h}$ of treatment with EAF (Table 5). Enhanced cell accumulation at the G0/G1 phase was in the range of 1.3-1.7 fold higher than that of control cells. Thus, cell accumulation takes place in G0/G1 phase proliferation by EAF was comparable to the quercetin (1.6 fold) at their maximum concentrations. Similarly, reduction of cell population by EAF at the $S$ phase proliferation was also 2.3 fold lower than that of control values $(47.25 \pm 3.00)$. These results clearly explored that the cell cycle arrest was takes place at the G0/G1 phase.

Using the annexin V-FITC assay kit, four groups of cells were estimated by the flow cytometry (Fig. 3a). The total apoptotic cells including addition of early and late apoptosis were observed after $48 \mathrm{~h}$ treatment with ethyl

Table 3 TAA and RAA of solvent fractions of ethanol extract of T. conoides

\begin{tabular}{|c|c|c|c|c|}
\hline \multirow[t]{2}{*}{ Solvent fractions } & \multirow{2}{*}{$\begin{array}{l}\text { Concentration } \\
(\mu \mathrm{g} / \mathrm{mL})\end{array}$} & \multirow[t]{2}{*}{ TAA (\%) } & \multicolumn{2}{|l|}{ RAA } \\
\hline & & & Beta -Carotene & L. Ascorbic acid \\
\hline \multirow[t]{4}{*}{ Hexane } & 10 & $08 \pm 0.84$ & 0.104 & 0.111 \\
\hline & 20 & $15 \pm 1.00$ & 0.195 & 0.208 \\
\hline & 40 & $30 \pm 1.41$ & 0.390 & 0.416 \\
\hline & 80 & $46 \pm 2.00$ & 0.597 & 0.637 \\
\hline \multirow[t]{4}{*}{ Dichloromethane } & 10 & $13 \pm 1.00$ & 0.169 & 0.180 \\
\hline & 20 & $23 \pm 1.70$ & 0.299 & 0.319 \\
\hline & 40 & $35 \pm 2.10$ & 0.455 & 0.485 \\
\hline & 80 & $55 \pm 1.92$ & 0.714 & 0.762 \\
\hline \multirow[t]{4}{*}{ Ethyl acetate } & 10 & $26 \pm 2.21$ & 0.338 & 0.360 \\
\hline & 20 & $46 \pm 2.00$ & 0.597 & 0.637 \\
\hline & 40 & $65 \pm 2.44$ & 0.844 & 0.900 \\
\hline & 80 & $85 \pm 1.84$ & 1.104 & 1.177 \\
\hline \multirow[t]{4}{*}{ water } & 10 & $05 \pm 0.70$ & 0.065 & 0.069 \\
\hline & 20 & $11 \pm 1.00$ & 0.143 & 0.152 \\
\hline & 40 & $25 \pm 1.00$ & 0.325 & 0.346 \\
\hline & 80 & $35 \pm 2.10$ & 0.455 & 0.485 \\
\hline
\end{tabular}


Table 4 In-vitro antioxidants profile of ethyl acetate fraction of ethanol extract of $T$. conoides

\begin{tabular}{lccc}
\hline EAF & & & \\
$(\mu \mathrm{g} / \mathrm{ml})$ & \multicolumn{2}{l}{ Antioxidant activities $(\%)$} & Uric acid formation inhibitory activity \\
\cline { 2 - 4 } & Superoxide radical scavenging activity & Iron chelation activity & $15 \pm 3.67$ \\
\hline 10 & $23 \pm 2.92$ & $16 \pm 3.08$ & $28 \pm 4.12$ \\
40 & $41 \pm 5.43$ & $36 \pm 5.70$ & $47 \pm 4.06$ \\
80 & $57 \pm 4.47$ & $50 \pm 4.69$ & $66 \pm 6.67$ \\
\hline
\end{tabular}

Mean + standard error $(n=5)$; EAF ethyl acetate fraction

acetate fraction of $T$. conoides. Total apoptotic cells were found to be $14-42 \%$ at the $80-320 \mu \mathrm{g} / \mathrm{mL}$ of concentrations. However, treatment with EAF showed statistically $(p<0.05)$ significant increase of apoptotic cells than that of quercetin $(32 \%, 160 \mu \mathrm{g} / \mathrm{mL})$. The result shows that it was concentration dependent (Fig. 3d). In addition, changes in the morphology of cancer cells due to condensation of nuclei and also alteration of mitochondrial membrane potential $(\Delta \Psi \mathrm{m})$ by EAF were detected with Hoechst and JC-1 stains by fluorescence microscopy, respectively (Fig. 3b \& c). These results supported further to confirm apoptosis induced by EAF of T. conoides.

\section{Discussion}

It is well known that cancer is the second major cause of death in the worldwide. Thus, leads to search new drugs of natural products from marine source that could contribute to overcome other treatment strategies of cancer like radiation therapy. In the present study was aimed to explore the antibacterial, antioxidant and anticancer properties of $T$. conoides through evaluating cytotoxicity, cell cycle arrest and apoptosis in HepG2 cell line. Brown seaweeds are commercially important renewable resources because which are possessed enormous amount secondary metabolites of potential bioactive compounds such as terpenoid, phlorotanins, phenolic, flavonoids, fucoidans,

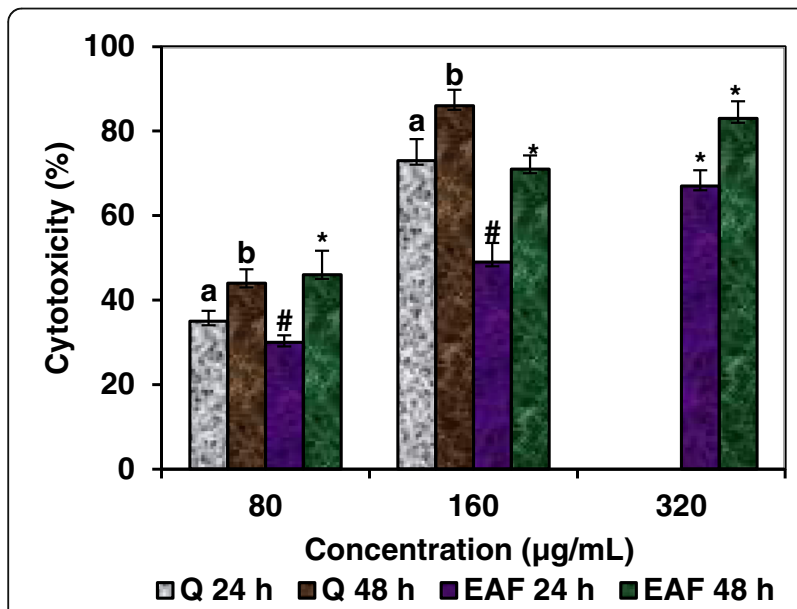

Fig. 1 Cytotoxicity of ethyl acetate fraction of T. conoides on HepG2 cell line sterols and glycolipids are extensively documented [11]. Screening of secondary metabolites in the present study was showed that the except resins and alkaloid, all other secondary metabolites were found to be presence in the ethanol extract of $T$. conoides (Table 1). There are three clinically important gram-positive and 8 gram-negative bacteria were used for the screening of antibacterial activity of $T$. conoides. Among the solvent fractions, EAF of ethanol extract of $T$. conoides exhibited highest antibacterial activity which was comparable to the standard, streptomycin against Bacillus subtilis, Enterococcus faecalis and Pseudomonas aeruginosa. Antibacterial activity of streptomycin showed in the range of $18-32 \mathrm{~mm}$ diameter zone of inhibition against all the tested bacteria (Table 2). Out of four solvent fractions, petroleum ether extract reported to be showed effective antibacterial activity [27]. Similar report revealed that the antimicrobial activity of $T$. conoides was in dose dependent for all four extracts and their highest activity exhibited in $500 \mu \mathrm{g} / \mathrm{mL}$ against all the tested pathogens [28]. Antibacterial activity of T. conoides was mainly due to secondary metabolites like phenolic compounds which may affect growth and metabolism of bacteria. These metabolites could explore inhibiting effect on microbial growth based on their chemical constitutions and concentrations [29].

In-vitro antioxidant activity measured by single assay is reflects the chemical reactivity under the specific conditions. Therefore, it is necessary to assay the solvent fractions through various methods revealed an overall idea about their broad spectrum of antioxidant activity [11]. The principal of assays based on quantification and radical scavenging property by different mechanisms viz., donating hydrogen molecule, electron transfer, reducing ability and metal ion chelating ability also considered. In the investigation, TAA was found to be $(85 \%, 80 \mu \mathrm{g} / \mathrm{mL})$ highest in EAF of $T$. conoides which was $1.9,1.6$ and 2.4 fold higher than that of $\mathrm{HF}, \mathrm{DMF}$ and $\mathrm{AF}$, respectively. Even TAA at $40 \mu \mathrm{g} / \mathrm{mL}$ of EAF was better than that of other three fractions. At the maximum concentration, TAA of EAF was comparable to the standard of $\beta$-carotene $(77 \%, 7.5 \mathrm{M} / \mathrm{mL})$ and ascorbic acid $(15 \mathrm{M} /$ $\mathrm{mL}$ ) (Table 3). TAA of DMF was showed (55\%, $80 \mu \mathrm{g} / \mathrm{mL}$ ) second highest than that of $\mathrm{HF}$ and AF. 


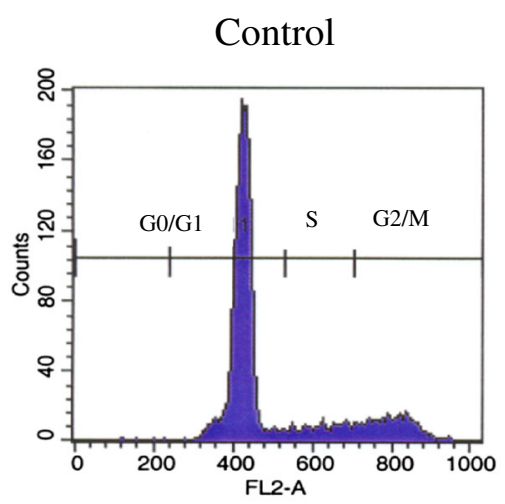

$\operatorname{EAF}(320 \mu \mathrm{g} / \mathrm{mL})$

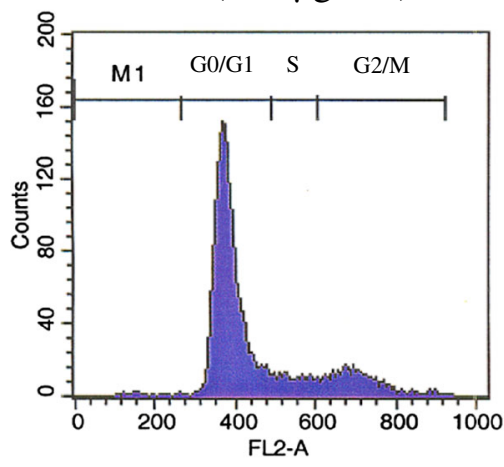

Quercetin $(160 \mu \mathrm{g} / \mathrm{mL})$

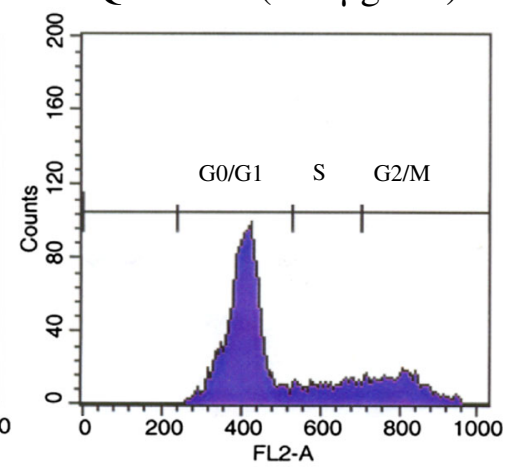

Fig. 2 Ethyl acetate fraction of T. conoides induces G0/G1 phase arrest in HepG2 cell line

However, EAF alone showed RAA $\geq 1$ against $\beta$ carotene and ascorbic acid when compared to the other fractions. This was clearly indicate that ethyl acetate fraction exhibit potential antioxidant activity than that of other fractions of $T$. conoides. Recent reports indicated that activity of EAF mainly due to the presence of phenolics like catechin and epigallocatechin. Other antioxidant compounds inculding fucoxanthin, astaxanthin, polyphenols, phlorotannins, phospholipids, flavonoids, bromophenols and polysaccharides were also documented [30, 31].

Superoxide radical scavenging activity, Iron chelation and uric acid inhibition assays were determined using

Table 5 Effect of ethyl acetate fraction of T. conoides on cell arrest in HepG2 cell line

\begin{tabular}{llll}
\hline $\begin{array}{l}\text { EAF Conc. } \\
(\mu \mathrm{g} / \mathrm{ml})\end{array}$ & \multicolumn{3}{l}{ T. conoides on cell cycle (\%) } \\
\cline { 2 - 4 } & $\mathrm{G}_{0} \mathrm{G}_{1}$ & $\mathrm{~S}$ & $\mathrm{G}_{2} \mathrm{M}$ \\
\hline 0 & $38.42 \pm 1.52$ & $47.25 \pm 3.00$ & $14.16 \pm 1.56$ \\
80 & $48.73 \pm 2.90$ & $35.18 \pm 1.39$ & $15.25 \pm 1.62$ \\
160 & $57.90 \pm 2.09$ & $25.79 \pm 1.30$ & $15.28 \pm 1.38$ \\
320 & $66.79 \pm 1.57$ & $20.15 \pm 0.99$ & $13.90 \pm 0.53$ \\
Conc. $(\mu \mathrm{g} / \mathrm{ml})$ & Quercetin on cell cycle $(\%)$ & \\
160 & $63.11 \pm 1.18$ & $24.29 \pm 2.00$ & $14.45 \pm 1.12$ \\
\hline
\end{tabular}

Mean + standard error $(n=5)$; EAF ethyl acetate fraction, Conc. concentration
EAF alone based on TAA. Superoxide scavenging activity was found to be in the range of $23-77 \%$ at the concentration of $10-80 \mu \mathrm{g} / \mathrm{mL}$. Highest concentration of EAF showed 3.4 fold higher activities over the lower concentration $(10 \mu \mathrm{g} / \mathrm{mL})$. Similarly, Iron chelation and uric acid inhibition activities of EAF were observed in the range of 15-70\% which showed 4.4 fold higher than that of their lower concentration $(10 \mu \mathrm{g} / \mathrm{mL})$. EAF of $T$. conoides was showed concentration dependent activity in all the case. Reducing power exhibited by solvent extracts of Turbinaria spp. was comparatively higher than $\alpha$-tocopherol [32]. In general, ferrous iron $\left(\mathrm{Fe}^{2+}\right)$ can stimulate and accelerate lipid peroxidation. As a result chelators of ion can be considered as potential inhibitors of lipid peroxidation. It was reported that bioactive compounds like phenolic acids, flavonoid, quercetin, and phenolic glycosides are potentially participate to chelate metal ions [11].

Cytotoxicity assay has been considered as the cell killing property of a chemical compound which is independent mechanism from the programmed cell death [33]. Cytotoxicity of EAF of T. conoides was observed to be significantly comparable to the standard of quercetin at all the concentration tested. Cytotoxicity was in the range of $30-83 \%$ and $35-86 \%$ in both EAF and quercetin, respectively. Cytotoxicity of highest concentration $(80 \mu \mathrm{g} / \mathrm{mL})$ was showed $\sim 2$ fold higher activity 
a

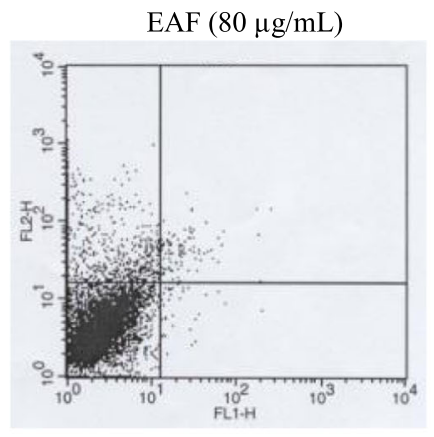

EAF $(320 \mu \mathrm{g} / \mathrm{mL})$

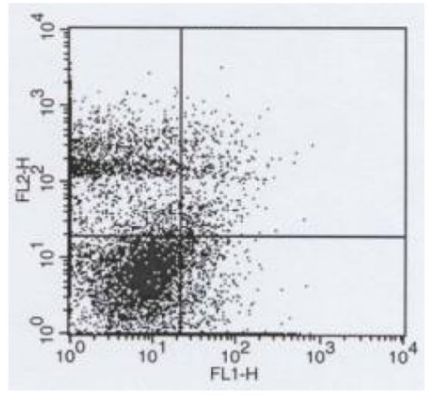

$\operatorname{EAF}(160 \mu \mathrm{g} / \mathrm{mL})$

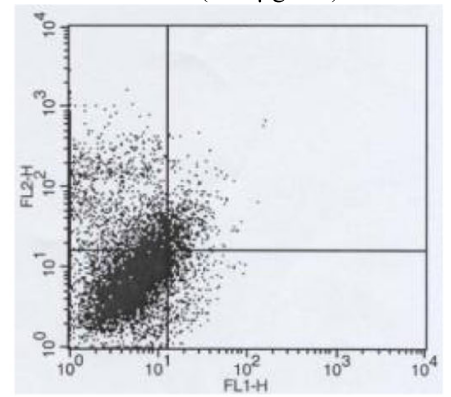

Quercetin $(160 \mu \mathrm{g} / \mathrm{mL})$

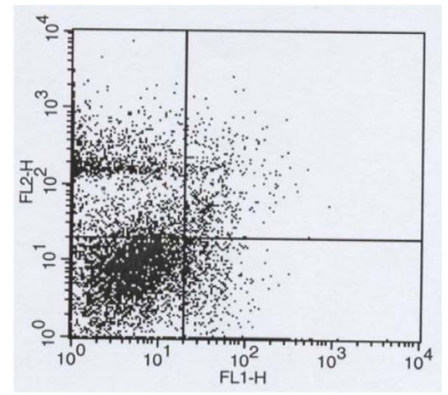

A - Annexin -V FITC b $\quad \operatorname{EAF}(320 \mu \mathrm{g} / \mathrm{mL})$

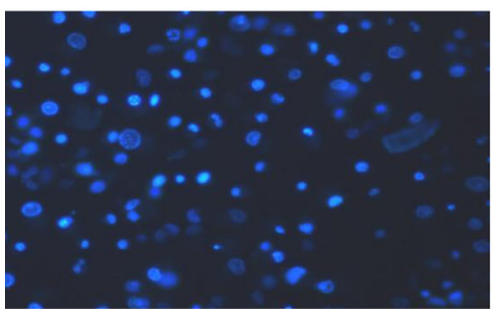

C

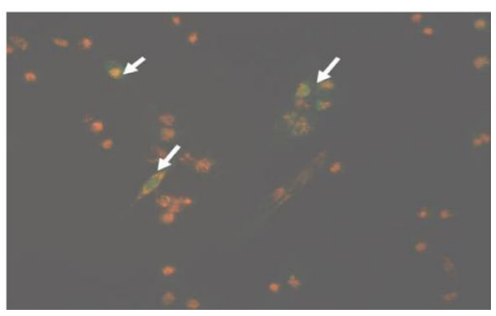

d

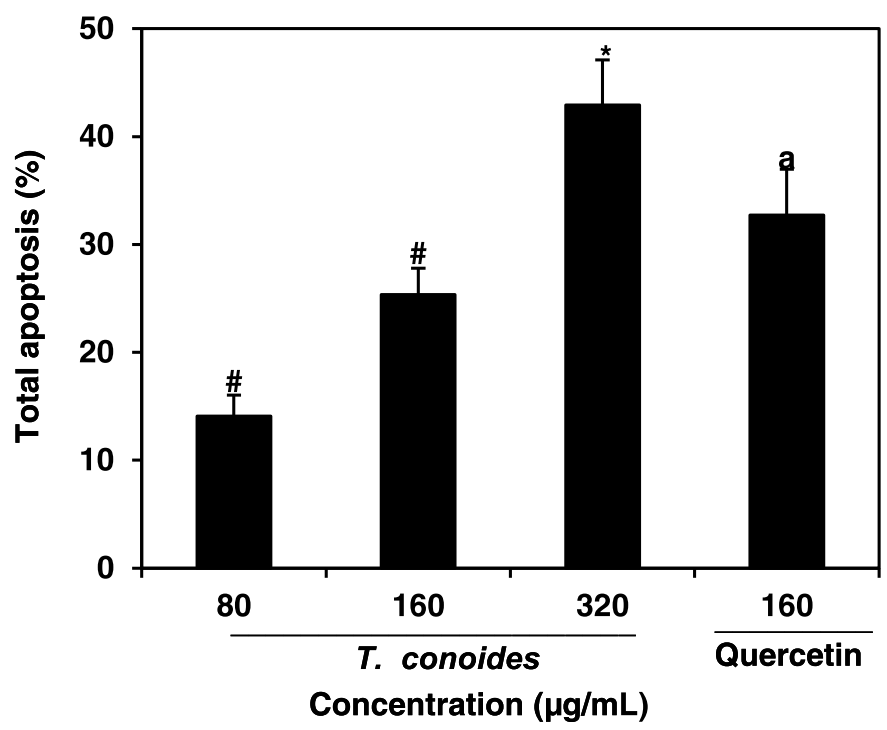

Fig. 3 (See legend on next page.) 
(See figure on previous page.)

Fig. 3 Ethyl acetate fraction of ethanol extract of T. conoides induces apoptosis in HepG2 cells. a Cells treated with EAF (0-320 $\mu \mathrm{g} / \mathrm{mL})$ for $48 \mathrm{~h}$ and staining with annexin-V FITC/PI. Each quadrant indicates the percentage of normal cells (annexin V-/PI-), early apoptosis (annexin V+/PI-) and late apoptosis (annexin $\mathrm{V}+/ \mathrm{PI}+$ ). b \& c Apoptotic cells through alteration of nuclear morphology and mitochondrial membrane potential $(\Delta \psi \mathrm{m})$ by EAF $(320 \mathrm{\mu g} / \mathrm{mL})$ treatment for 48 were visualized in HepG2 cells with Hoechst 33342 and JC-1 stains by fluorescence microscopy, respectively. The later, red fluorescence indicates mitochondria with intact membrane potential and green fluorescence indicates de-energized mitochondria

than that of lower concentration $(20 \mu \mathrm{g} / \mathrm{mL})$. Cytotoxicity of various extract obtained from a variety algae collectively demonstrated that the brown algae have a potential source of compounds presenting biological activities on tumor cells [34]. Cytotoxicity and antioxidant activity of EAF were found to be well correlated and concentration dependent.

Cell cycle analysis revealed that the number of accumulated cancer cells was significantly $(p<0.05)$ higher in the proliferative G0/G1 phase and a significant decrease in the $S$ phase, after $48 \mathrm{~h}$ of treatment with EAF of $T$. conoides. At the highest concentration of EAF and quercetin were observed to be enhanced the cell accumulation $\leq 1.74$ fold in the G0/G1 phase over the zero concentration. Hence, the cell population was found to be decreased $\leq 2.4$ fold in the $S$ phase over the zero concentration. In the current reports revealed that the cell cycle arrest was taken place in the G0 and M phase and most of the cytokinetic and pharmacological research was also shows accurate cell cycle analysis [35]. Other report revealed that cell cycle arrest leads to increase in sub-G0/G1cell population after treatment with increasing doses of linalool terpenoid [36]. Phlorotanninsenriched extract of brown alga of $H$. grandifolius exhibited cytotoxicity against tumor cell line including Hep-2 and promoting cell death trough apoptosis mechanisms [34].

The effects of EAF of $T$. conoides on apoptosis of HepG2 cells were determined using annexin V-FITC and PI staining. Phosphatidyl serine (PS) is located on the cytoplasmic surface of the normal cell whereas in apoptotic cells, located in the outer leaflet of the plasma membrane. Annexin-V is a $35-36 \mathrm{kDa} \mathrm{Ca} 2$ +-dependent phospholipid binding protein that has a high affinity for PS. In addition, the red-fluorescent PI is a nucleic acid binding dye which is impermeant to live cells and early apoptotic cells but stains dead cells with red fluorescence. After staining a cell population with annexin V and PI, apoptotic cells shows green fluorescence, dead cells shows red and green fluorescence, and live cells shows little or no fluorescence (Fig. 3a). These populations can easily be distinguished using a flow cytometer [26]. However, treatment with EAF showed (43\%) statistically $(p<$ $0.05)$ significant increase of apoptotic cells than that of quercetin standard $(32 \%, 80 \mu \mathrm{g} / \mathrm{mL})$. The highest concentration of EAF enhanced 3 fold of apoptotic cells over the lower concentration. Thus, the result shows that the total apoptotic cells were found to be concentration dependent and better than that of quercetin (Fig. 3d). Nuclear condensation by EAF of $T$. conoides exhibited morphological changes in the apoptotic cells with the Hoechst 33342 staining (Fig. 3b). There was a difference between the untreated HepG2 cells (weak homogeneous blue) and treated cells (bright chromatin condensation and nuclear fragmentation). In addition, the mitochondria membrane potential assay was further supported that the EAF of $T$. conoides inducing apoptosis in HepG2 cells. JC-1 probe is a fluorescent cationic dye that can selectively accumulate into mitochondria by electrochemical gradient and changes color from red to green as $\Delta \Psi \mathrm{m}$ decreases [25-35].

\section{Conclusion}

The brown algae have possessed beneficial effects on mankind which is obviously explored in the present study. Many reports revealed that the $T$. conoides exhibited antibacterial and antioxidant activities against different expediency methods. However, an anticancer property of $T$. conoides against various tumours was scanty. The brief results stated that ethanol extract of $T$. conoides possessed various secondary phytochemicals except resin and alkaloids. Among the four solvent fractions of ethanol extract, EAF showed higher antibacterial, TAA and RAA when compared to the respective standards. In addition, in-vitro anticancer activity of $T$. conoides revealed through exhibiting $30-83 \%$ cytotoxicity, 1.3-1.7 fold higher cell cycle arrests at the G0/G1 phase than control cells, $14-42 \%$ of apoptosis by altering nuclear condensation and also mitochondrial membrane potential $(\Delta \Psi \mathrm{m})$. Therefore, in the present study can help to increase the knowledge and extent the search of anticancer compounds further from the brown algae. It is essential to identify bioactive molecules in EAF and determining whether the anticancer activity due to single compound or synergistic compounds. Hence, further studies are required for the better understanding which molecules shows bioactiveness and which pathways are involved in programmed cell death.

\section{Abbreviations}

ABTS: 2,2'-azino-bis- (3-ethyl benzothiazoline-6-sulfonic acid); AF: Aqueous fraction; ASC: L-ascorbic acid; DMF: Dichloromethane; EAF: Ethyl acetate; 
EDTA: Ethylenediaminetetraacetic acid; FITC: Fluorescein isothiocyanate; HF: Hexane fraction; NBT: Nitroblue tetrazolium; PBS: Phosphate-buffered saline; PI: Propidium iodide; RAA: Relative antioxidant activity; SDS: Sodium dodecyl sulfate; TAA: Total antioxidant activity

\section{Acknowledgment}

This contributed research work was supported by University Grant Commission (UGC), Government of India, New Delhi (TAM -8496).

\section{Authors' contributors}

The authors of this study claim sole responsibility for the concepts included herein. All authors read and approved the final manuscript.

\section{Competing interests}

The authors declare that they have no competing interests

\section{Author details}

'Department of Zoology, School of Life Science, Bharathiar University, Coimbatore 641 046, Tamil Nadu, India. ${ }^{2}$ Centre for Advanced Studies in Botany, School of Life Science, University of Madras, Guindy, Chennai 600 113, Tamil Nadu, India. ${ }^{3}$ Department of Microbial Technology, School of Biological Science, Madurai Kamaraj University, Madurai 625 021, Tamil Nadu, India.

\section{Received: 22 September 2016 Accepted: 18 January 2017}

\section{Published online: 13 February 2017}

\section{References}

1. Gupta S, Abu-Ghannam N. Bioactive potential and possible health effects of edible brown seaweeds. Trends Food Sci Technol. 2011;22:315-26.

2. Ananthi S, Rao H, Raghavendran B, Sunil AG, Gayathri V, Ramakrishnan G, et al. In-vitro antioxidant and in-vivo anti-inflammatory potential of crude polysaccharide from Turbinaria ornate (Marine Brown Alga). Food Chem Toxicol. 2010;48:187-92.

3. Liu L, Heinrich M, Myers S, Dworjanyn SA. Towards a better understanding of medicinal uses of the brown seaweed Sargassum in Traditional Chinese Medicine: a phytochemical and pharmacological review. J Ethnopharmacol. 2012;142:591-619.

4. Lee JC, Hou MF, Huang HW, Chang FR, Yeh CC, Tang JY, et al. Marine algal natural products with anti-oxidative, anti-inflammatory, and anti-cancer properties. Cancer Cell Inter. 2013;13:55.

5. Gamze Y, Serap C, Ozgur V, Sukran D. Determination of the anti-oxidative capacity and bioactive compounds in green seaweed Ulva rigida C. Agardh. Int J Food Prop. 2011:11:44-52.

6. Jyh-Horng S, Guey-Horng W, Ping-Jyun S, Chang-Yih D. New cytotoxic oxygenated fucosterols from the brown Alga Turbinaria conoides. J Nat Prod. 1999;62(2):224-7.

7. Nabanita C, Ghosh T, Sinha S, Kausik C, Karmakar P, Bimalendu R. Polysaccharides from Turbinaria conoides: structural features and antioxidant capacity. Food Chem. 2010;118(3):823-9.

8. Rajeshkumar S, Malarkodi C, Gnanajobitha G, Paulkumar K, Vanaja M, Kannan K, Annadurai G. Seaweed-mediated synthesis of gold nanoparticles using Turbinaria conoides and its characterization. J Nanostructure Chem. 2013;3:44.

9. Fitton $\mathrm{JH}$, Stringer DN, Karpiniec SS. Therapies from fucoidan: an update. Mar Drugs. 2015;13:5920-46.

10. Ananthi S, Gayathri V, Veeresh Kumar S, Meenakshi B, Vasanthi HR. Attenuation of inflammation by marine algae Turbinaria ornata in cotton pellet induced Granuloma mediated by fucoidan like sulphated polysaccharide. Carbohydr Polym. 2016;151:1261-8.

11. Chakraborty K, Praveen NK, Vijayan KK, Syda Rao G. Evaluation of phenolic contents and antioxidant activities of brown seaweeds belonging to Turbinaria spp. (Phaeophyta, Sargassaceae) collected from Gulf of Mannar. Asian Pac J Trop Biomed. 2013;3(1):8-16.

12. $\mathrm{Hu} X$, Jiang $X$, Hwang $H$, Liu S, Guan $H$. Antitumour activities of alginate-derived oligosaccharides and their sulphated substitution derivatives. Eur J Phycol. 2004;39:67-71.

13. Shahidi F. Nutraceuticals and functional foods: whole versus processed foods. Trends Food Sci Tech. 2009;0:376-87.

14. Jemal A, Bray F, Ferlay J, Ward E, Forman D. Global cancer statistics. CA Cancer J Clin. 2011;61:69-90.
15. Fabregat I. Dysregulation of apoptosis in hepatocellular carcinoma cells. World Gastroenterol J. 2009:15:513-20.

16. Khan N, Adhami VM, Mukhtar H. Apoptosis by dietary agents for prevention and treatment of prostate cancer. Endocr Relat Cancer. 2010;17:39-52.

17. Gupta P, Bansal MP, Koul A. Spectroscopic characterization of lycopene extract from Lycopersicum esculentum (Tomato) and its evaluation as a chemopreventive agent against experimental hepatocarcinogenesis in mice. Phytother Res. 2013;27(3):448-56.

18. Arumugam P, Ramamurthy P, Santhiya ST, Ramesh A. Antioxidant activity measured in different solvent fractions obtained from Mentha spicata linn.: ananalysis by $\mathrm{ABTS}^{+}$decolorization assay. Asia Pacific J Clin Nutr. 2006;15:20-4

19. Allen ST. Chemical analysis of ecological material. New York: Blackwell Scientific Publication; 1974. p. 313.

20. Harbone JR. Phytochemical methods. A guide to modern techniques of plant analysis. London: Charpan and Hall; 1976. p. 78.

21. Mackeen MM, Ali AM, El-sharkawy SH, Manap MY, Salleh KM, Lajis NH, Kawazu K. Antimicrobial and cytotoxic properties of some Malaysian traditional vegetables. Pharmace Biol. 1997;35:174-8.

22. Tota S, Kumura M, Ohnishi M. Effects of phenol carboxylic acids on superoxide anion and lipid peroxidation induced by superoxide anion. Planta Med. 1991:57:8-10.

23. Decker EA, Welch B. Role of ferritin as lipid oxidation catalyst in muscle food. J Agric Food Chem. 1990;38:674-7.

24. Mosmann TJ. Rapid colorimetric assay for cellular growth and survival: Application to proliferation and cytotoxicity assays. J Immolunol Meth 1983;65:55-63.

25. Darzynkiewicz Z, Bedner E, Smolewski P. Flow cytometry in analysis of cell cycle and apoptosis. Sem Hematol. 2001;38:179-93.

26. Liu TY, Tan ZJ, Jiang L, Gu JF, Wu XS, Cao Y, et al. Curcumin induces apoptosis in gallbladder carcinoma cell line GBC-SD cells. Cancer Cell Inter. 2013;13:64.

27. Sridharan MC, Dhamotharan R. Antibacterial activity of marine brown alga Turbinaria conoides. J Chem Pharmaceut Res. 2012;4(4):2292-4.

28. Senthilkumar P, Sudha S. Antibacterial properties of Turbinaria conoides from Gulf of Mannar Coast. Int J Pharm Sci Rev Res. 2012;17(1):74-6.

29. Vijayabaskar P, Shiyamala V. Antibacterial activities of brown marine Algae (Sargassum wightii and Turbinaria ornata) from the Gulf of Mannar Biosphere Reserve. Adv Bio Res. 2011;5(2):99-102.

30. Gupta S, Abu-Ghannam N. Recent developments in the application of seaweeds or seaweed extracts as a means for enhancing the safety and quality attributes of foods. Innov Food Sci Emerg Technol. 2011;12:600-9.

31. Umayaparvathi S, Arumugam M, Balasubramanian T, Meenakshi S. In-vitro antioxidant properties and FTIR analysis of two seaweeds of Gulf of Mannar. Asian Pac J Trop Biomed. 2012;1 Suppl 1:S66-70.

32. Kumar CS, Ganesan P, Bhaskar N. In-vitro antioxidant activities of three selected brown seaweeds of India. Food Chem. 2008;107:707-13.

33. Jin X, Chen Q, Tang SS, Zou JJ, Chen KP, Zhang T, Xiao XL. Investigation of quinocetone-induced genotoxicity in HepG2 cells using the comet assay, cytokinesis-block micronucleus test and RAPD analysis. Toxicol In Vitro. 2009;23:1209-14.

34. Gambato G, Caroline OS, Frozza ÉG, Baroni MS, et al. Brown Algae Himantothallus grandifolius (Desmarestiales, Phaeophyceae) Suppresses Proliferation and Promotes Apoptosis-Mediated Cell Death in Tumor Cells. Adv Bio Chem. 2014:4:98-108.

35. Qiu L, Liu M, Pan K. A triple staining method for accurate cell cycle analysis using multiparameter flow cytometry. Molecules. 2013;18:15412-21.

36. Sun XB, Wang SM, Li T, Yang YQ. Anticancer activity of Linalool Terpenoid: apoptosis induction and cell cycle arrest in prostate cancer cells. Tropic J Pharmaceut Res. 2015;14(4):619-25. 